\title{
Perbaikan Penjadwalan Aktivasi Starter Pack Untuk Meminimasi Keterlambatan Dengan Menggunakan Metode Earliest Due date Pada PT XYZ
}

\author{
Riska Retno Widyaningsih ${ }^{\left({ }^{* *}\right)}$ Budi Sulistyo ${ }^{(2)}$, Murni Dwi Astuti ${ }^{(3)}$ \\ ${ }^{(1,2,3)}$ Jurusan Teknik Industri,Universitas Telkom, Bandung \\ Email : riska.retno@gmail.com ${ }^{(1)}$
}

\begin{abstract}
Abstrak
PT XYZ merupakan salah satu perusahaan yang bergerak di bidang jasa telekomunikasi, produk starter pack, dan voucher pulsa. Permasalahan yang terjadi pada PT XYZ yaitu keterlambatan aktivasi starter pack digudang regional yang menyebabkan terjadinya waktu tunggu pengambilan starter pack oleh retailer. Permasalahan keterlambatan terjadi karena belum adanya kebijakan penjadwalan pasti, sehingga belum adanya penentuan prioritas job. Pada penelitian ini, akan dikembangkan kebijakan penjadwalan termasuk pembagian job setiap mesin per hari dan pengurutan pengerjaan job. Metode yang digunakan adalah earliest due date. Pada metode ini akan ditentukan urutan pengerjaan job berdasarkan due date terkecil yang berpengaruh terhadap waktu penyelesaian suatu job. Penjadwalan dilakukan terhadap satu mesin yang mengerjakan enam job dalam satu minggu. Data yang digunakan adalah data aktivasi starter pack periode Oktober 2014. Berdasarkan perhitungan kondisi eksisting, terdapat keterlambatan 7.8 jam pada job Site Jakarta dan 15.3 jam pada job Site Surabaya. Waktu proses dan due date setiap job akan menjadi inputan dalam metode yang digunakan. Hasil dari perhitungan kondisi usulan di PT XYZ dengan menggunakan metode earliest due date mampu menurunkan keterlambatan aktivasi starter pack hingga 38\% dibanding kondisi eksisting. Waktu penyelesaian 6 job dalam satu minggu pada kondisi eksisting 30.3 jam menjadi 18.3 jam pada kondisi usulan.
\end{abstract}

Kata Kunci: aktivasi, earliest due date. penjadwalan, starter pack

\begin{abstract}
PT XYZ is one of the company that move in telecommunications services, starter pack products, and vouchers. The problems in PT XYZ is lateness of starter pack activation in regional warehouse that cause waiting time of starter pack's pick up by retailer. Lateness problem happened because there is no fixed scheduling policy yet, so there is no determination of job's priority. In this research will be developed scheduling policies including job allocation each machine per day and sequencing of job. The method used is the earliest due date. In this method, job sequence will be determined based on the smallest due that influence the Completion time of a job. Scheduling do for one machine that doing six jobs in one week. The data used is the starter pack activation data in October 2014. Based on the existing calculations condition, there is a delay of 7.8 hours on job Site s in Jakarta and 15.3 hours on job Site s Surabaya. Processing time and due date of each job are the input in the methods used. The results of calculation of the proposed conditions in PT XYZ by using a method capable of lowering the earliest due date delay activation up to $38 \%$ compared to the existing condition. Completion time of 6 job in a week with the existing condition is 30.3 hours to 18.3 hours on the proposed conditions.
\end{abstract}


Keyword : activation, earliest due date, scheduling, starter pack

\section{Pendahuluan}

Perkembangan telekomunikasi pada tahun-tahun terakhir ini sangat berkembang pesat. Perkembangan telekomunikasi yang pesat dibuktikan dengan perkembangan handphone. Handphone adalah alat telekomunikasi yang memiliki perkembangan akses data dimulai dari $2 \mathrm{G}$ hingga LTE. Rata-rata penduduk Indonesia paling sedikit memiliki dua handhphone yang menyebabkan permintaan handhphone di Indonesia meningkat [1]. Perusahaan telekomunikasi merasakan dampak peningkatan jumlah permintaan handphone yaitu memenuhi kebutuhan pendamping handphone. Kebutuhan pendamping handphone adalah SIM Card (starter pack) dan voucher yang berfungsi untuk operasional dan fungsional komunikasi dengan handphone [2], [3]. PT XYZ merupakan perusahaan yang bergerak di bidang telekomunikasi dengan melayani konsumen dalam jasa telekomunikasi. Produk dan fasilitas yang disediakan yaitu jaringan telekomunikasi, voucher dan media telekomunikasi (starter pack). PT XYZ memiliki 11 gudang regional dari Sabang sampai Merauke untuk mendukung pemenuhan kebutuhan starter pack yang meningkat akibat meningkatnya permintaan handphone di Indonesia [4]. Gudang regional PT XYZ antara lain Sumbagut, Sumbagteng, Sumbagsel, Jabotabek, Jabar, Jateng, Jatim, Bali nusa, Kalimantan, Sulawesi dan Papua. PT XYZ memiliki proses distribusi untuk mendukung pemenuhan permintaan starter pack. Gambar 1.2 adalah proses distribusi dari gudang pusat ke retailer [5]-[7]. Proses distribusi dimulai dari gudang regional membuat purchase order, kemudian purchase order diserahkan ke gudang pusat. Gudang pusat melakukan konfirmasi ketersediaan starter pack ke gudang regional. Gudang regional mengirim laporan permintaan aktivasi starter pack ke channel pusat berdasarkan konfirmasi ketersediaan pengiriman barang oleh gudang pusat. Channel pusat melakukan aktivasi starter pack dan gudang pusat mengirim starter pack ke gudang regional di waktu yang sama, artinya waktu yang diberikan untuk aktivasi starter pack berdasarkan lama waktu pengiriman starter pack dari gudang pusat ke regional [1]. Setelah starter pack sampai di gudang regional dan starter pack telah sukses diaktivasi, gudang regional melakukan konfirmasi ke retailer untuk mengambil starter pack di gudang regional [8]-[10]. Penyebab keterlambatan pengambilan starter pack oleh retailer disebabkan oleh keterlambatan penyelesaian aktivasi starter pack Hal ini dibuktikan dengan perbandingan presentase keterlambatan yang disebabkan aktivasi starter pack dan distribusi fisik starter pack [11], [12], [13].

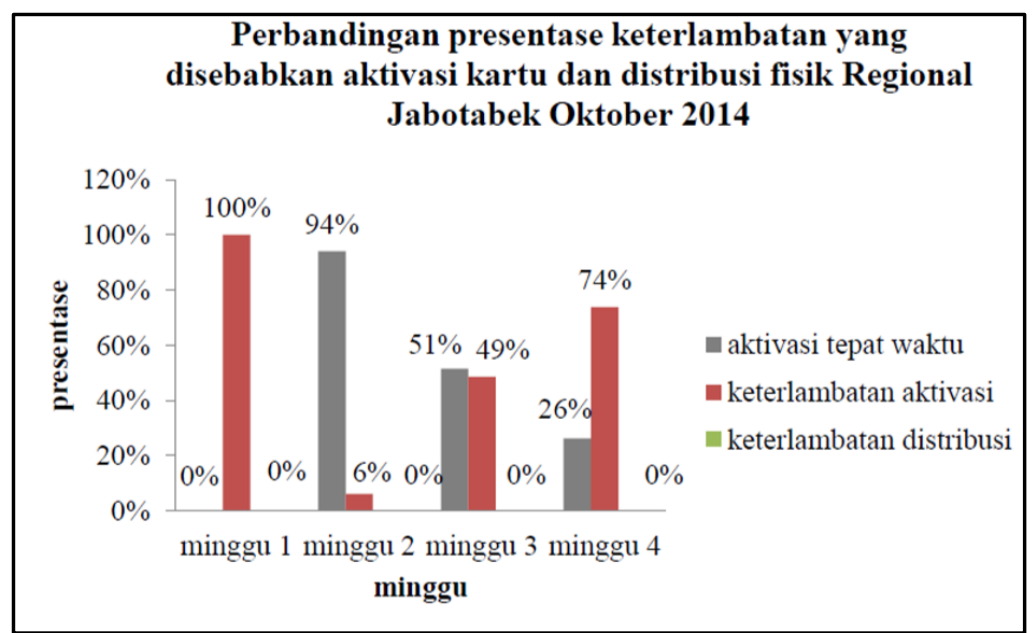

Gambar 1 Perbandingan Presentase Keterlambatan Yang Disebabkan Oleh Aktivasi Starter Pack dan Distribusi Fisik Starter Pack

PT XYZ memiliki peraturan bahwa starter pack tidak dapat diambil oleh retailer jika starter pack belum selesai diaktivasi oleh channel pusat. Retailer harus menunggu pengiriman starter pack 
lebih dari waktu yang telah ditentukan jika aktivasi terlambat. Waktu tunggu retailer mengindikasi lost sales karena starter pack tidak dapat dijual ketika starter pack masih berada di gudang regional[14]

PT XYZ menggunakan cara aktivasi parsial dan aktivasi fully pada aktivasi starter pack. Aktivasi fully adalah aktivasi starter pack yang dilakukan dalam satu waktu untuk satu kali permintaan pada satu regional. Aktivasi parsial ialah aktivasi starter pack yang dilakukan sebagian dari total permintaan dan sisanya diaktivasi di lain waktu [15]. PT XYZ masih menggunakan cara aktivasi parsial. Aktivasi parsial menyebabkan keterlambatan terhadap Site (job) yang memiliki due date kecil karena pembagian job aktivasi starter pack yang dilakukan melebihi due date. Aktivasi parsial ini terjadi karena banyaknya traffic atau antrian pada aktivasi starter pack yang masih dilayani dengan sistem parsial [16].

Jika kondisi antrian aktivasi starter pack berlangsung terus-menerus akan mengakibatkan kerugian pada PT XYZ karena banyaknya produk yang tidak terjual pada waktunya atau lost sales. Permasalahan pada aktivitas ini merupakan permasalahan penjadwalan karena berhubungan dengan menentukan jadwal job di satu mesin dengan waktu yang ada sehingga tidak terjadi keterlambatan. Proses aktivasi dilakukan oleh dua jenis mesin yaitu mesin HLR dan mesin OCS. Mesin HLR melakukan job dengan cara paralel dan mesin OCS melakukan job dengan cara bergantian, kedua mesin tidak saling memiliki dependensi dan kedua jenis mesin ini memiliki responsibilitas divisi yang berbeda. Mesin HLR terdapat 11 unit untuk mengerjakkan 11 job dengan kecepatan 5000 ID per dua detik dan mesin OCS memiliki 1 unit untuk mengerjakan 6 job dengan kecepatan 100.000 ID per jam. Perbedaan kecepatan dan kapasitas kedua mesin ini menyebabkan perbedaan jumlah produksi yang dihasilkan.. Divisi provisioning telah melakukan penjadwalan aktivasi starter pack mesin OCS dan mesin HLR untuk aktivasi starter pack [17]. Namun, divisi provisioning masih mengalami keterlambatan dalam aktivasi starter pack. Keterlambatan aktivasi disebabkan mesin OCS yang masih menggunakan sistem parsial dalam melakukan aktivasi dengan kecepatan dan kapasitas mesin OCS yang terbatas. Sistem parsial menyebabkan regional yang memiliki due date lebih awal tidak dikerjakan terlebih dahulu sampai selesai dan mengalami keterlambatan [18]. Oleh karena itu, diperlukan optimasi dalam penjadwalan mesin OCS agar permintaan dapat dipenuhi tepat waktu [19], [20].

Tabel 1 Keterlambatan Setiap Site

\begin{tabular}{|c|c|c|}
\hline Site (job) OCS & Regional & Lama Keterlambatan (jam) \\
\hline \multirow{2}{*}{ Surabaya } & Jawa Timur & \multirow{2}{*}{15,3} \\
\cline { 2 - 2 } & Jawa Barat & \multirow{2}{*}{7,8} \\
\cline { 2 - 2 } & Jawa Tengah & 0 \\
\hline Jabotabek & Jakarta & \multirow{2}{*}{0} \\
\hline Palangkaraya & Balinusra & \multirow{2}{*}{0,7} \\
& Papua & \multirow{2}{*}{0,7} \\
\hline \multirow{2}{*}{ Pekanbaru } & Sumbagut & 0 \\
\cline { 2 - 2 } & Sumbagteng & 0 \\
\hline Banjarmasin & Sumbagsel & 0 \\
\hline Makassar & Kalimantan & \\
\hline
\end{tabular}

Pada Tabel 1 terlihat bahwa keterlambatan terjadi pada regional yang memiliki due date paling kecil, sehingga usulan penjadwalan dilakukan terhadap 11 regional. Penjadwalan aktivasi juga memerlukan improvement sehingga penjadwalan usulan dapat sesuai dengan proses aktivasi starter pack [18], [21]. Proses aktivasi starter pack memerlukan usulan perbaikan dalam penjadwalan yang tepat dan sesuai untuk mengatasi keterlambatan aktivasi starter pack [19]. 


\section{Metode Penelitian}

Pada penelitian ini diawali dengan melakukan pengamatan langsung terhadap divisi provisioning dan hasil wawancara langsung terhadap karyawan PT XYZ. Hasil pengamatan adalah didapatkan data mengenai jumlah aktivasi setiap hari, jadwal aktivasi yang sudah ditetapkan, waktu proses tiap job dan mesin yang digunakan untuk aktivasi. Data-data tersebut akan dijadikan input dalam proses penjadwalan dengan menggunakan metode earliest due date. Parameter input ini akan menentukan urutan penyelesaian job. Kemudian urutan penyelesaian pekerjaan akan dikemas ke dalam penjadwalan. Pada tahap pendahuluan, observasi dilakukan terhadap obyek yang akan di teliti. Observasi dilakukan dengan cara studi lapangan dan studi literatur [22].

Studi lapangan dan studi literatur dilakukan untuk mengetahui permasalahan yang ada dan perlu di perbaiki. Studi lapangan adalah observasi secara langsung di area obyek dengan kontak fisik penglihatan, pendengaran dan perabaan misalkan wawancara dan pengamatan obyek. Studi literatur berupa referensi mengenai obyek yang diteliti berupa modul yang digunakan pada obyek, jurnal dan buku. Setelah menemukan inti permasalahan pada obyek dan materi yang sesuai dengan permasalahan, permasalahan dapt dibentuk menjadi sebuah topik penelitian. Topik penelitian akan di rumuskan pada perumusan masalah dengan menetapkan batasan masalah agar bahasannya tidak melebar [23]. Selain itu juga menetapkan tujuan penelitian untuk menandakan bahwa penelitian sudah selesai jika sudah dapat memenuhi tujuan yang ditetapkan.

Pada tahap pengumpulan data, data yang dikumpulkan berupa data tertulis seperti dokumen maupun hasil wawancara yang dapat mendukung penelitian. Data yang diperlukan adalah sebagai berikut :

1. Data waktu proses Data waktu proses diperlukan untuk menghitung waktu yang diperlukan dengan urutan eksisting sehingga ditemukan waktu total yang diperlukan untuk aktivasi pada mesin yang ada. Hasil tersebut dapat ditemui makespan yang terjadi.

2. Data Jumlah starter pack untuk aktivasi Data jumlah starter pack yang diperlukan untuk aktivasi sebagai bahan pembagian tugas pada jumlah unit mesin yang tersedia sehingga dapat menjadi input penjadwalan agar penggunaan mesin dapat dilakukan secara adil dan waktu yang optimal sesuai dengan kapasitas mesin yang tersedia.

3. Data due date Data due date diperlukan untuk waktu proses maksimal yang diperlukan sebagai acuan minimasi makespan pada pengerjaan job. Data due date setiap job akan berbeda sesuai dengan kebutuhan customer.

4. Data penalti keterlambatan Data penalti keterlambatan merupakan waktu yang diperlukan di luar waktu proses maksimal atau melebihi due date. Data penalti keterlambatan dapat disebut sebagai makespan yang terjadi pada suatu pengerjaan job.

Selanjutnya adalah tahap perumusan model permasalahan dimana dilakukan penentuan fungsi tujuan dari suatu penelitian. Fungsi tujuan yang dipakai adalah minimasi lateness sehingga diperlukan input untuk pengolahan data menggunakan teorema earliest due date. Input ini akan diolah sesuai dengan langkah-langkah pengolahan data menggunakan metode earliest due date. Penentuan solusi dengan menggunakan metode earliest due date membutuhkan input dan langkahlangkah yang harus dilalui. Langkah-langkah pengolahan data menggunakan metode earliest due date untuk mencari solusi urutan baru pengerjaan job $\mathrm{m}$ pada mesin dengan minimasi lateness. Pada tahap penentuan kebijakan penjadwalan membuat kebijakan penjadwalan berdasarkan solusi urutan pengerjaan job pada mesin. Solusi ini akan dituangkan kepada pembagian tugas pengerjaan setiap hari kerja dalam seminggu.

Tahap analisis merupakan tahap menilai hasil yang didapatkan dari pengolahan data yang telah dilakukan. Tahap analisis pada penelitian ini terdiri dari dua poin utama, yaitu analisis penentuan pengoptimalisasian penjadwalan ,dan analisis jadwal eksisting, analisis jadwal usulan dan analisis perbandingan antara jadwal eksisting dan jadwal usulan. Analisis akan dilakukan terhadap metode penjadwalan lengkap yang telah dibuat. Selain itu, melakukan analisis impelementasi dari usulan proses perencanaan aktivasi untuk melihat perbaikan apa yang dapat diberikan dengan penerapan model penjadwalan yang diusulkan pada keadaan eksisting yang terjadi di PT XYZ. Kemudian analisis perbandingan antara solusi usulan proses aktivasi dengan proses eksisting. Tahap kesimpulan dan saran merupakan tahap terakhir dalam penelitian ini. Pada tahap ini berisi kesimpulan-kesimpulan yang merujuk pada tujuan yang ingin dicapai dalam penelitian ini yang didasarkan pada analisis yang telah 
dilakukan. Selain itu, terdapat saran yang ditujukan untuk penelitian selanjutnya dengan menerapkan earliest due date pada penjadwalan produksi.

\section{Hasil dan Pembahasan}

Pengolahan data eksisting yaitu mengetahui keterlambatan (lateness) yang didapatkan dari selisih waktu penyelesaian (completion time) yang dibutuhkan oleh 6 job dalam satu minggu dan due date yang ditentukan untuk ke 6 Site (job). Jika nilai lateness bernilai positif maka terjadi keterlambatan dan jika nilai lateness bernilai negatif, maka tidak terjadi keterlambatan. Pengolahan data untuk mengetahui keterlambatan dan meminimasi keterlambatan dengan menggunakan metode earliest due date. Tabel 2 adalah perhitungan lateness pada penjadwalan eksisting minggu pertama.

Tabel 2 Perhitungan Lateness Eksisting Minggu 1

\begin{tabular}{|c|c|c|c|}
\hline Task 1 & $\begin{array}{c}\text { Completion time Ci } \\
\text { (hour) }\end{array}$ & $\begin{array}{c}\text { Due date di } \\
\text { (hour) }\end{array}$ & Lateness Li (hour) \\
\hline SRB & 30,3 & 15 & 15,3 \\
\hline BJM & 21,4 & 35 & $-13,6$ \\
\hline PLG & 21,5 & 40 & $-18,5$ \\
\hline JKT & 22,8 & 15 & 7,8 \\
\hline PKB & 25,7 & 25 & 0,7 \\
\hline MKR & 25 & 35 & -10 \\
\hline
\end{tabular}

PT XYZ memiliki satu mesin untuk mengerjakan enam job. Terdapat lateness tiap Site . Lateness positif menunjukkan keterlambatan dan lateness negatif menunjukkan aktivasi yang tidak terlambat. Lateness maksimum yang dihasilkan pada aktivasi minggu pertama adalah 15.3 jam dengan waktu yang digunakan 30.3 jam dalam satu minggu. Berikut adalah Gambar 2 (Gantt Chart) yang menerangkan tentang .

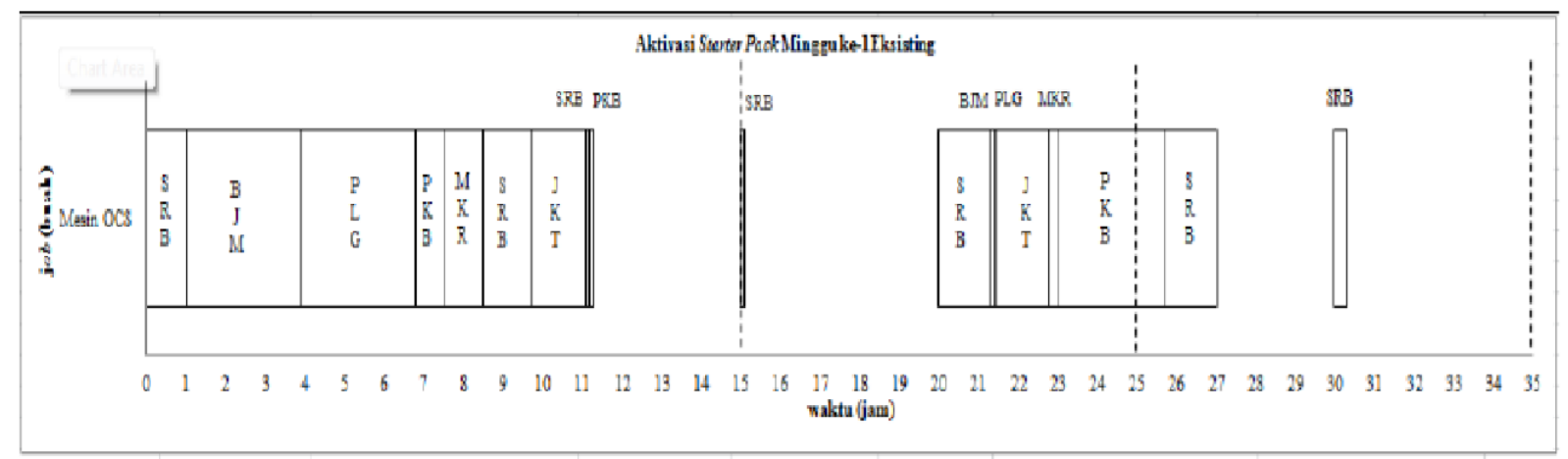

Gambar 2 Gantt Chart Aktivasi Starter Pack Eksisting Minggu ke-1

Gambar 2 menunjukkan jumlah starter pack dan waktu yang dipakai untuk aktivasi setiap hari. Divisi OCS masih menggunakan sistem parsial dalam melakukan aktivasi sehingga jumlah starter pack dan waktu yang diperlukan setiap hari dalam seminggu selalu berubah-ubah. Perbedaan jumlah dan waktu ini menyebabkan kondisi yang tidak menentu yaitu kadang-kadang mesin bekerja dalam satu hari penuh bahkan harus dilanjutkan keesokan harinya dan kadang-kadang aktivasi tidak penuh satu hari karena penjadwalan yang dibuat divisi provisioning tidak penuh. Penjadwalan aktivasi starter pack menggunakan metode earliest due date. Data yang dibutuhkan untuk perhitungan yaitu Completion time dan due date. Completion time adalah merupakan rentang waktu antara saat pekerjaan itu dimulai sampai pekerjaan itu selesai dan due date adalah waktu maksimal penyelesaian suatu proses yang telah ditentukan sebelumnya. Lateness didapatkan dari selisih antara Completion time dan due date. Tabel 3 merupakan perhitungan lateness menggunakan metode earliest due date : 
Tabel 3 Perhitungan lateness usulan menggunakan earliest due date minggu ke-1

\begin{tabular}{|c|c|c|c|c|}
\hline Job & $\begin{array}{c}\text { Processing time } \mathrm{t} \\
(\mathrm{jam})\end{array}$ & $\begin{array}{c}\text { Completion time } \\
\mathrm{Ci}(\mathrm{jam})\end{array}$ & Due date di (jam) & Lateness Li (jam) \\
\hline Jakarta & 4,6 & 2,6 & 15 & $-12,4$ \\
\hline Surabaya & 8,2 & 10,8 & 15 & $-4,2$ \\
\hline Pekanbaru & 3,2 & 14 & 25 & -11 \\
\hline Banjarmasin & 1 & 15 & 35 & -20 \\
\hline Makassar & 1,8 & 16,8 & 35 & $-18,2$ \\
\hline Palangkaraya & 1,9 & 18,7 & 40 & $-21,3$ \\
\hline
\end{tabular}

Pada Tabel 3 menunjukkan bahwa semua lateness bernilai negatif, itu artinya perhitungan menggunakan earliest due date dapat meminimasi lateness. Perhitungan earliest due date dapat meminimasi makespan sebesar 11.6 jam dari makespan awal 30.3 menjadi 18.7 jam. Gambar 3 merupakan Gantt Chart yang menerangkan Tabel 3. Pada Gambar 3 menunjukkan waktu aktivasi starter pack yang diperlukan lebih kecil daripada waktu eksisting dan waktu yang dibutuhkan untuk aktivasi kurang dari due date yang telah ditentukan sebelumnya. Minimasi makespan disebabkan oleh penukaran pengurutan pengerjaan job aktivasi dan prioritas pengerjaan job berdasarkan due date yang paling kecil. Selain itu, antara job satu dengan job yang lain tidak ada waktu menganggur untuk mesin kecuali di luar jam operasional, sehingga job dapat dipadatkan di awal minggu dan memiliki waktu sisa di akhir minggu. Waktu sisa ini dapat dimanfaatkan untuk kegiatan lain yang membutuhkan waktu lebih lama. Gantt Chart aktivasi starter pack usulan minggu ke-1.

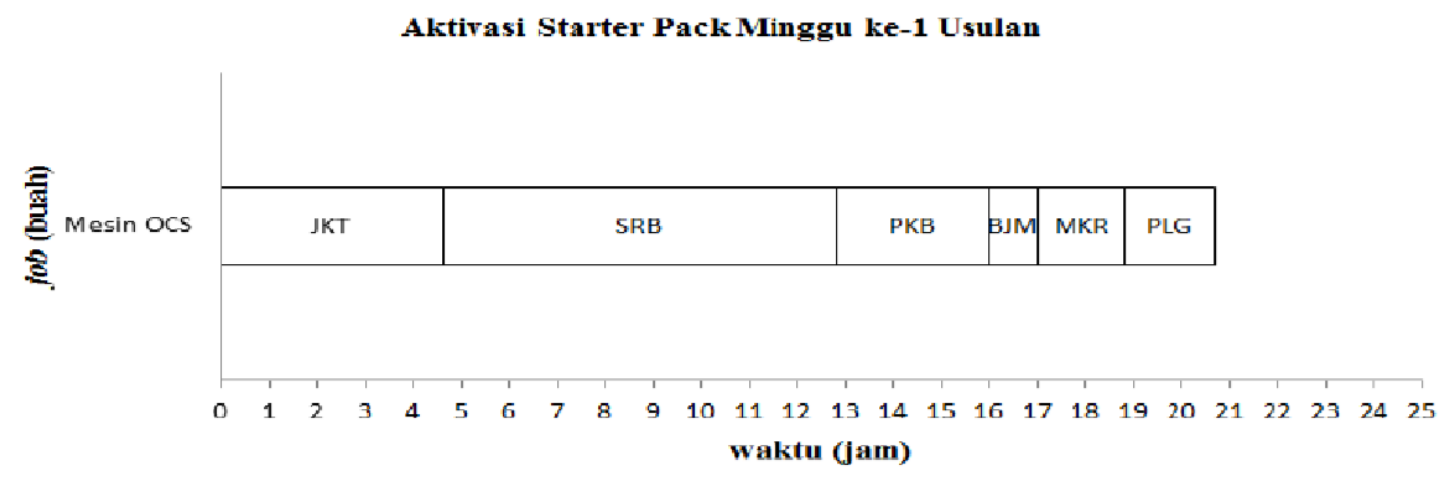

Gambar 3 Gantt Chart Aktivasi Starter Pack Usulan Minggu ke-1

Setelah dilakukan penjadwalan aktivasi usulan dengan menggunakan metode earliest due date maka terjadi pencapaian pemenuhan permintaan aktivasi starter pack yang baru. Tabel 4 adalah data presentase pencapaian pemenuhan permintaan aktivasi starter pack menggunakan metode earliest due date. 
Tabel 4 Presentase Pencapaian Pemenuhan Permintaan Aktivasi Starter Pack menggunakan metode earliest due date

\begin{tabular}{|c|c|c|c|c|c|}
\hline \multirow{2}{*}{ Site (Job) } & \multicolumn{5}{|c|}{ Periode aktivasi bulan Oktober 2014 (minggu) } \\
\cline { 2 - 6 } & $\mathrm{Ke}-1$ & $\mathrm{Ke}-2$ & $\mathrm{Ke}-3$ & $\mathrm{Ke}-4$ & $\mathrm{Ke}-5$ \\
\hline Jakarta & $100 \%$ & $100 \%$ & $100 \%$ & $100 \%$ & $100 \%$ \\
\hline Surabaya & $100 \%$ & $100 \%$ & $100 \%$ & $100 \%$ & $100 \%$ \\
\hline Pekabaru & $100 \%$ & $100 \%$ & $100 \%$ & $100 \%$ & $100 \%$ \\
\hline Banjarmasin & $100 \%$ & $100 \%$ & $100 \%$ & $100 \%$ & $100 \%$ \\
\hline Makassar & $100 \%$ & $100 \%$ & $100 \%$ & $100 \%$ & $100 \%$ \\
\hline Palangkaraya & $100 \%$ & $100 \%$ & $100 \%$ & $100 \%$ & $100 \%$ \\
\hline Total & $100 \%$ & $100 \%$ & $100 \%$ & $100 \%$ & $100 \%$ \\
\hline
\end{tabular}

Hasil waktu proses eksisting aktivasi starter pack untuk Site (job) Surabaya, Site Jakarta, Site Banjarmasin, Site Palangkaraya, Site Makasar dan Site Pekanbaru pada minggu ke-1. Selain mendapatkan waktu proses job dari hari senin sampai job hari minggu, didapatkan jumlah dan waktu lateness yang terjadi. Lateness disebabkan oleh waktu proses yang dikerjakan lebih besar daripada due date yang telah ditentukan. Makespan yang dihasilkan oleh job-job pada minggu pertama adalah 30.3 jam. Makespan pada minggu pertama terdapat lateness maksimum sebesar 15.3 jam. Urutan job berdasarkan sistem parsial adalah SBY-BJM-PLG-JKT-PKB-MKR. Keterlambatan penyelesaian job terjadi di Site Surabaya dan Site Jakarta karena Site Jakarta dan Site Surabaya memiliki due date yang singkat namun job pada Site Surabaya dan Site Jakarta dikerjakan setelah due date atau tidak dikerjakan terlebih dahulu sampai selesai, sedangkan Site lain yang memiliki due date lebih besar dikerjakan terlebih dahulu. Waktu proses usulan aktivasi starter pack untuk job Site Surabaya, Site Jakarta, Site Banjarmasin, Site Palangkaraya, Site Makasar dan Site Pekanbaru pada minggu ke-1. Solusi usulan yang digunakan adalah merapatkan semua job ke waktu yang paling awal dan menukarkan job-job yang memiliki due date lebih awal untuk diprioritaskan.

Merapatkan job di waktu awal adalah solusi terbaik karena memaksimalkan waktu yang tersedia untuk aktivasi, sehingga waktu sisa dapat digunakan untuk kegiatan lain yang membutuhkan waktu lebih lama. Selain itu, memprioritaskan job yang memiliki due date lebih awal juga meminimasi lateness karena jika job yang memiliki due date lebih awal tidak dikerjakan terlebih dahulu akan terjadi keterlambatan dan job lain yang memiliki due date lebih panjang akan menganggur jika dikerjakan lebih awal. Hasil dari perbandingan ialah perhitungan metode earliest due date menghasilkan perubahan lateness sebesar 38\%. Tabel 5adalah perbandingan dan penurunan lateness antara waktu proses eksisting dengan waktu proses menggunakan metode earliest due date.

Tabel 5 Perbandingan Lateness eksiting dan lateness usulan

\begin{tabular}{|c|c|c|c|c|}
\hline & Makespan eksiting & Makespan usulan & Lateness eksiting & Lateness usulan \\
\hline MI & $30,3 \mathrm{jam}$ & $18,7 \mathrm{jam}$ & $15,3 \mathrm{jam}$ & 0 jam \\
\hline
\end{tabular}

Perbedaan lateness antara kondisi eksisting dan kondisi menggunakan metode earliest due date menyebabkan perubahan yang terjadi pada kondisi perusahaan. Perubahan tersebut dapat dilihat dari salah satu aspek yaitu jumlah aktivasi dan jumlah persediaan di gudang. Jumlah aktivasi starter pack semakin besar yang dapat diaktivasi jika waktu dapat diminimasi. Selain itu, persediaan gudang regional dapat ditekan dari over stock karena persediaan starter pack dapat diberikan ke retailer tepat waktu. Keputusan dilihat dari nilai lateness yang paling kecil antara kondisi eksisting dan metode earliest due date memiliki perbedaan lateness yang besar. Solusi urutan job dengan menggunakan metode earliest due date yaitu JKT-SBY-PKB-BJM-MKR-PLG. Dalam menyusun jadwal aktivasi yang baru diperlukan penyesuaian peraturan yang berlaku di PT XYZ tersebut agar penjadwalan layak (feasible) untuk dilaksanakan. Penyesuaian peraturan perusahaan yaitu menghapus peraturan sistem aktivasi parsial. 
Analisis pemilihan metode earliest due date menjelaskan bahwa metode earliest due date memperbaiki masalah pada perusahaan. Keputusan tersebut perlu dilakukan peninjauan ulang dari berbagai aspek dan dilihat berbagai kelebihan dan kekurangan pada usulan penjadwalan menggunakan metode tersebut. Maka dari itu berbagai aspek akan dibahas pada bagian di bawah ini:

1. Produksi Perubahan jumlah aktivasi starter pack jika dibandingkan dengan kondisi eksisting perusahaan. Metode earliest due date dapat meminimasi lateness sebesar 38\%. Namun dilihat dari kondisi aktual perusahaan terdapat faktor eksternal yang menyebabkan keterlambatan sehingga hal ini dapat dijadikan suatu pertimbangan metode yang digunakan perusahaan.

2. Perubahan dari kondisi eksisting menjadi kondisi menggunakan metode earliest due date akan mempengaruhi beban kerja pada pekerja. Penjadwalan usulan menyebabkan pekerja harus bekerja lebih sibuk di awal periode minggu. Namun, perubahan beban kerja hanya berpengaruh sedikit pada kesulitan beban kerja karena terdapat waktu luang pada akhir minggu. Pekerja masih dapat beroperasi seperti kondisi eksisting hanya dengan menambah beban kerja pada awal minggu sehingga produksi makin meningkat. Selain itu, mesin di kerjakan oleh outsource sehingga sulit untuk melakukan pekerjaan secara langsung dan harus melalui koordinasi dahulu. Sistem outsource dapat menjadi bahan pertimbangan metode yang digunakan perusahaan.

Usulan metode yang diajukan adalah penjadwalan dengan metode earliest due date. Penjadwalan usulan mempunyai berbagai kekurangan dan kelebihan. Penjelasan mengenai kekurangan dan kelebihan metode penjadwalan sebagai berikut:

1. Kelebihan

a. Adanya penjadwalan yang dapat meminimasi lateness pada perusahaan.

b. Dapat melakukan produksi job lainnya diluar enam job yang diteliti sehingga dapat menaikan jumlah produksi pada perusahaan atau menambah job lain

2. Kekurangan

a. Perubahan lateness yang besar memberikan waktu menganggur mesin di akhir minggu (periode). Selain perubahan lateness, dapat dilakukan dengan alternatif lain seperti penambahan mesin namun hal tersebut memerlukan biaya yang mahal.

b. Ada perubahan peraturan atau regulasi perusahaan dalam menentukan perencanaan penjadwalan.

\section{Kesimpulan}

Setelah dilakukan pengolahan data dan analisis maka dapat ditarik berbagai kesimpulan. Kesimpulan yang dapat diambil dari penelitian ini adalah:

1. Penjadwalan usulan metode earliest due date dapat meminimasi lateness. Pada penelitian ini didapatkan hasil perhitungan menggunakan metode earliest due date dengan makespan sebesar 18.7 jam dari makespan pada kondisi eksisting 30.3 jam, sehingga dapat meminimasi 11.6 jam dari kondisi eksisting perusahaan dengan urutan penjadwalan yaitu JKT-SBY-PKBBJM-MKR-PLG.

2. Metode earliest due date mempunyai makespan yang lebih singkat dan memiliki performance yang lebih baik dari kondisi eksisting. Metode earliest due date dilihat dari menghilangkan lateness maksimum eksisting sebesar 15.3 jam. 


\section{Daftar Pustaka}

[1] J. Xiang, Konsumsi Ponsel di Indonesia Sudah Menggila. 2014.

[2] M. Date, High Field Magnetism. North Holland, 1983.

[3] M. McDonald, K. Ward, and B. Smith, Marketing Due Diligence. Butterworth-Heinemann, 2005.

[4] S. Tabrizi, S. H. Ghodsypour, and A. Ahmadi, "Modelling three-echelon warm-water fish supply chain: A bi-level optimization approach under Nash-Cournot equilibrium," Appl. Soft Comput., vol. 71, pp. 1035-1053, Oct. 2018.

[5] D. R. Kneeland, S. V. Nablo, D. E. Weiss, and T. E. Sinz, "Industrial use of the real time monitor for quality assurance in electron processing," Radiat. Phys. Chem., vol. 55, no. 4, pp. 429-436, Jul. 1999.

[6] P. Kotler, "Reinventing marketing to manage the environmental imperative," Journal of Marketing. 2011.

[7] L. M. Ellram and M. L. Ueltschy Murfield, "Supply chain management in industrial marketingRelationships matter," Ind. Mark. Manag., vol. 79, pp. 36-45, May 2019.

[8] P. Amuthabala and R. Santhosh, "Robust analysis and optimization of a novel efficient quality assurance model in data warehousing," Comput. Electr. Eng., vol. 74, pp. 233-244, Mar. 2019.

[9] Eprints, "Lean Warehouse," eprintsugm. [Online]. Available: http://eprints.umg.ac.id/1089/2/BAB 2.pdf.

[10] A. Wijaya, T. W. Panjaitan, and H. C. Palit, "Healty and Safety Management System," 1998. [Online]. Available: http://publication.petra.ac.id/index.php/teknik-industri/article/view/2979.

[11] D. Benson and G. Whitehead, Transport and Distribution. Made Simple, 1975.

[12] J. Id, “Arti Branding dalam Sebuah Produk," jurnla id, 2017. [Online]. Available: https://www.jurnal.id/id/blog/2017-semua-tentang-branding-yang-harus-anda-tahu/. [Accessed: 14-Sep-2019].

[13] Q. Yang, T. Yang, and W. Li, Smart Power Distribution Systems. Academic Press, 2018.

[14] D. D. Bedworth and J. E. Bailey, Integrated Production Control Sistems. New York: John Wiley \& Sons, Inc, 1987.

[15] K. R. Baker, Prinsiples of Sequencing and Scheduling. A John Wiley \& Sons, INC, 2009.

[16] P. W. Budi Santosa, Metoda Metaheuristik Konsep dan Implementasi. Guna Widya, 2011.

[17] M. A. Intan Berlianty, Teknik-Teknik Optimasi Heuristik. Graha Ilmu, 2005.

[18] R. Ginting, Penjadwalan Mesin. Yogyakarta: Graha Ilmu, 2009.

[19] H. P. Sri Kusuma Dewi, Penyelesaian Masalah Optimasi dengan Teknik-teknik Heuristik. Graha Ilmu, 2005.

[20] E. P. Ainaro, A. Gadri, S. E. Priani, P. M. Lendir, B. Achatina, and F. Bowdich, "Formulasi Sediaan Masker Gel Peel-Off Mengandung Lendir Bekicot (Achatina Fulica Bowdich) sebagai Pelembab Kulit," in Prosiding Penelitian SPeSIA Unisba 2015, 2015.

[21] A. M. Majid, P. Moengin, and A. Witonohadi, "USULAN PENERAPAN TOTAL PRODUCTIVE MAINTENANCE (TPM) DENGAN PENGUKURAN OVERALL 
EQUIPMENT EFFECTIVENESS (OEE) UNTUK PERENCANAAN PERAWATAN PABRIK BAR MILL PADA PT. KRAKATAU WAJATAMA,” J. Tek. Ind., 2014.

[22] H. Hasanah, "TEKNIK-TEKNIK OBSERVASI (Sebuah Alternatif Metode Pengumpulan Data Kualitatif Ilmu-ilmu Sosial)," At-Taqaddum, vol. 8, no. 1, p. 21, 2017.

[23] F. Gustiar, R. A. Suwignyo, . S., and . M., "Reduksi Gas Metan (CH4) dengan Meningkatan Komposisi Konsentrat dalam Pakan Ternak Sapi,” J. Peternak. Sriwij., 2014. 